\title{
Investigation on Image Encryption Using Chaos Based Techniques
}

\author{
Dr.R.Premkumar ${ }^{1} \mid$ Dr.C.Priya ${ }^{2} \mid$ S.Vengatesh kumar $^{2} \mid$ Dr.M.Vidhyalakshmi ${ }^{3} \mid$ Dr.S.Saranya ${ }^{4}$ \\ ${ }^{1}$ Electronics and Communication Engineering, Siddharth Institute of Engineering \& technology, Puttur, Tamilnadu, India. \\ ${ }^{2}$ Electronics and Communication Engineering, Mohamed Sathak Engineering college, Kilakarai, Tamil nadu, India. \\ ${ }^{3}$ Electronics and Communication Engineering, SRM Institute of technology,Ramapuram, Tamilnadu,India. \\ ${ }^{4}$ Electronics and Communication Engineering, Easwari Engineering college,Chennai, Tamilnadu,India.
}

\section{To Cite this Article}

Dr.R.Premkumar., Dr.C.Priya., S.Vengatesh Kumar., Dr.M.Vidhyalakshmi \& Dr.S.Saranya. Investigation on Image Encryption Using Chaos Based Techniques. International Journal for Modern Trends in Science and Technology 7, 147-153 (2021).

\section{Article Info}

Received on 18-April-2021, Revised on 11-May-2021, Accepted on 19-May-2021, Published on 22-May-2021.

\section{ABSTRACT}

As the trading of information over the open systems and internet is quickly developing, security of the information turns into a major concern. One conceivable answer for this issue is to encode the information. Chaos has been generally utilized for image encryption for its diverse elements. There are numerous chaotic based encryption procedures for information concealing like validation, hashing, cryptography have been created and are in practice nowadays. This paper moreover investigates the properties of various mapping techniques that stretches out to the execution parameters utilized as a part of encryption forms. Every one of the strategies checked on appeared inside the most recent years and are observed to be valuable for the present day encryption applications. Every system is one of a kind in its own specific manner, which may be reasonable for various applications. Over the long haul, new encryption strategies are advancing. Hence, quick and secure traditional encryption systems will be required in applications requiring high rate of security.

KEYWORDS: Mapping, Encryption, cryptography, frame work, Chaotic Map

\section{INTRODUCTION}

The encryption of information assumes a major role in securing the information in online transmission concentrates basically on its security. There are numerous encryption systems are exist which are utilized to keep away from the data theft. A method in which mystery (secret) messages are exchanged starting with one individual then onto the next over the correspondence line called cryptography. The technique(s) used to change over the first information into mystery code or information is called information encryption procedure for all sorts of information, for example, printed information, image information or mixed media information for secured correspondence over a system.

Image encryption using mapping techniques which has applications in web correspondence, mixed media frameworks, restorative imaging, telemedicine, military correspondence; and so on. Image encryption is not quite the same as the straightforward information encryption.

Chaotic techniques, in any case, show disorder for certain scope of estimations of their parameters. Because of wide application zones of chaos particularly in the fields of science and designing, it is imperative to understand its elements and the parameter values that lead to its rise in frameworks. 
Disorder is a standout amongst the most essential behavioral modes showed by dynamical frameworks and alludes to the flighty, apparently arbitrary, movement of directions of a dynamical framework.

\section{LITERATURE SURVEY}

The following image encryption techniques have been developed recently and are gaining wider acceptance in image security applications in many fields

\section{Intertwining Logistic Guide and Cellular Automata using Image Encryption Algorithm}

Manish Kumar and Sunil Kumar (2016) proposed the encryption calculation for image based on intertwining logistic guide and cellular automata. The scheme uses a combination of permutation and diffusion.

A disorder based irregular generator is utilized with the end goal that the encryption methodology gets difficult. Permutation procedure first shuffles the pixels and after that dispersion system multiplies a minor change in a pixel to the entire picture.

As the calculation relies on upon confused system, minor change in key results in absolutely particular yields. Key for the proposed framework can restrict animal power assault and works in commotion free transmission. Moreover key sensitivity analysis, histogram analysis, differential attack and different tests talked about in the paper recommends that the framework having high security.

\section{A Quick Image Encryption Algorithm in view of Chaotic Map}

In the work of Wenhiro Liu and Kehui Sun (2016), a fast encryption process for image is presented. Here 2D Sine IMIC Modulation map is proposed and its disorganized capacities are examined by stage chart, Lyapunov type range and many-sided quality. The perplexity and dissemination procedure are consolidated at the underlying phase of encryption procedure. Chaotic Shift Transform (CST) is used to shuffle the pixels of the picture very effectively, also line and segment substitution process are applied to shuffle the image pixels.

CST shows the better scrambling impact and low time many-sided quality. Here multiple keys are used, secret key with the length if 256 bits (i.e., key space of $2^{256}$ ) which is sufficiently much to beat savage power assault. A quick image encryption is done by combining both 2D-SIMM and CST. The proposed algorithm can resist security and time complexity analysis which includes statistical analysis, secret key analysis and differential attack and brute force attack. Hence it has better application prospects in picture or video correspondence.

\section{Safer Image Encryption Algorithm Utilizing Rubik's Cube and Chaotic Baker's Map}

Abitha K.A \& Pradeep K Bharathan (2016) work on implementation of a color image encryption calculation in the network which may have important data that must not be accessed by the unauthorized people. In this paper an efficient strategy for image encryption in view of Rubik's cube standard with chaotic Baker map is exhibited. It consists of two layers. The primary layer is a preprocessing layer used to enhance the security of the framework which is executed with the chaotic baker map. In the second layer, the Rubik's cube standard is used.

The actual image is initially changed over into baker mapped image and after that Rubik's cube standard is applied. The preprocessing layer is utilized to enhance the security level. It is simple and accomplishes great permutation and diffusion systems in sensible time. This scheme is implemented in MATLAB. The proposed framework will work effectively for image encryption and will give few advantages over existing frameworks. The calculation gives client adaptability by giving Encryption to an extensive variety of images.

The product gives the adaptability of picking standard organization image of any shape and size. Various analysis including histogram, correlation coefficient, MSE, NPCR and UACI values demonstrates lossless encryption and decryption is given by this calculation. There is no information loss during the procedure of encryption and decryption. Image quality is additionally maintained

\section{Chaos Based Encryption to Secure DICOM Image}

In this paper, Dhivya\&Padmapriya (2016) proposes encryption plan in view of joining different chaotic maps to guarantee the protected transmission of therapeutic pictures. The proposed method uses three different maps namely logistic, tent and sine maps. This scheme uses confusion and diffusion of DICO) image pixels.

The conventional security components sent in current medical frameworks are Advanced 
Encryption Standard (AES), Triple Data Encryption Standard (3DES) and International Data Encryption Algorithm (IDEA). In view of a couple of characteristic practices of DICOM, these conventional systems are less powerful or take colossal computational time to secure them with a specific end goal to acknowledge the sternness of the proposed method, the made chao-cryptic arrangement is subjected to various security investigation, for example, measurable, differential, key space, key affectability, deliberate scrambling attack and chose plaintext attack examinations.

Different systems have been utilized as a part of this paper to dissect and approve the security and unpredictability of the proposed plan, including measurable investigation, connection examination, differential investigation, key space, key affectability, deliberate trimming attack and picked plaintext attack examination. In this way the trial comes about have demonstrated that proposed DICOM cryptosystem improved an alluring measure of assurance for continuous restorative image security applications.

\section{Information Concealing Technique Based on Chaos Implanted Genetic Algorithm for Color Image}

In this paper, SengulDogan (2016) developed a new algorithm for Data hiding which is broadly utilized as a part of data security. In information concealing applications, optimization procedures are used keeping in mind the end goal to enhance the achievement of calculations. The genetic algorithm is used to a great extent utilizing heuristic improvement methods as a part of these applications. Based on genetic algorithm, chaotic map is used to enhance the information concealing method. Arbitrariness of genetic is performed by utilizing different chaotic maps.

The different mapping includes Logistic map, Tent map, Chebyshev map, Cubic map, Sinus map, Circle map Henon map, ICMIC map, Sinusoidal map and Gauss map. Peak Signal to Noise Ratio (PSNR) is picked as the fitness function. The achievement of the proposed technique is given near results. It shows that gauss, logistic and tent maps are quicker than arbitrary capacity for proposed information concealing technique and are better according to step number.

\section{2D-Logistic Adjusted Sine Map (2D-LASM) Based Image Encryption}

Zhong Yun Hua \&Yicong Zhou (2016) proposes two dimensional logistic adjusted sine maps. The guideline of dissemination and disarray are totally satisfied and an arrangement of adding sporadic qualities to plain-picture is planned to update the security level of figure picture. Execution evaluations show that it has better ergodicity and flightiness, and a more extensive confused extent than numerous current chaotic maps.

Key are generated to enhance security and to oppose the savage power attack, key space of a disorderly based encryption technique should be greater than $2^{\wedge} 100$. To satisfy this prerequisite and change in accordance with the structure of LAS-IES, we set the puzzle key as 232 bits. The encoded comes about reliably have the same representation position as the interesting pictures. Subsequently, LAS-IES can be connected to mechanized photos of any organizations. It contains three guideline parts, particularly, including encompassing pixels, bit control perplexity, and bit control dissemination.

The adding neighboring pixels are to add discretionary qualities to the plain-picture to ensure that each mixed result is unmistakable. Distinctive rounds of perplexity and dispersion are performed in the bit level to fulfill the rule of disarray and dissemination. Generation results and security examination showed that LAS-IES can scramble unmistakable sorts of images into irregular like ciphered image of high security levels.

\section{Dynamic S-Box Based Image Encryption Plan}

P.Devaraj\&C.Kavitha (2016) proposes chaos based picture encryption arrangement using altered standard guide. The arrangement has two stages: the perplexity stage in which pixel stage and component $\mathrm{s}$-box substitution rearranges the photo and modifies the pixel values, the dissemination stage where dispersion is finished in a sporadic configuration. A disorderly key succession is made using the changed standard guide. The arrangement is proposed to be dependent on this disorderly grouping. The scheme is implemented in MATLAB for simulations. S box is constructed, every line and segment of the s-box are generated by distinctive permutations of whole numbers from 1 to 16 .

Conceivable stages with numbers 1 to 16 from which just 16 distinct changes are determined for the lines of the s-box. Examination utilizing entropy, histogram, connection, NPCR and UACI values exhibits that the changed standard guide together with element s-box substitution makes the 
arrangement strong and secure against measurable and differential assault.

\section{A Steganographic Strategy Using Bernoulli's Chaotic Map}

Richardo Francisco \& Ruben Vazquez (2015) propose an option for building an information concealing algorithm into computerized pictures (digital images). The strategy depends on chaos theory and the least significant bit method for installing a mystery message in a picture. Particularly the Bernoulli's chaotic maps are utilized, to play out the accompanying processes:(i) encrypt the bits of the message before installing them into the spread picture (ii) a arbitrary choice of the picture's compositions(R, G or B) must be performed and the insertion of the mystery message arbitrarily to (iii) rows and (iv) columns of the picture.

A chaotic map is utilized to alter the statistical behavior of the message before concealing it. This last chaotic map gives an obscure impact to the classified message before implanting, which prompts the main layer of security. The proposed steganographic technique scrambles the delicate information utilizing an essential stream figure utilizing a chaotic map and pseudo-randomizes the pixel determination utilizing other two chaotic maps for inserting the encoded sensitive information.

Several experimental results are appeared under changed assessment criteria, such as entropy, auto correlation, homogeneity, contrast, energy, peak signal to-noise ratio, mean squared error and greatest supreme squared deviation. Experimental results demonstrate a good improvement in the peak-signal-to-noise-ratio and image fidelity estimation of the proposed algorithm in contrast with the outcomes acquired from comparative algorithms.

\section{Execution of New System for Image Encryption utilizing Arnold 3D Cat Map}

The work by Kunal Kumar Kabi\&Arun Chauhan (2015) focuses on implementation of encryption algorithm for images based on Arnold 3D cat map. Chaotic maps are helpful to guarantee security since they are easy to create, are deterministic and are extremely hard to predict. This scheme is composed of substitution and diffusion process. In the substitution stage, chaotic map is used to rearrange the picture pixels. In dispersion stage, pixel qualities are modified successively so that the change made to a specific pixel relies on upon the past pixels. The actual image is encrypted using both the Arnold 2D and 3D cat maps. The effectiveness of this encryption has been checked by the histogram analysis. Likewise, the security of this method has been assessed against the differential attacks utilizing NPCR and UACI values. The result demonstrates that the proposed strategy gives better security and resistant to the basic differential attacks.

\section{A Chaos Based Image Encryption Algorithm with Basic Consistent Functions}

In this paper, ErdemYavuz\&RifatYazici (2015) proposes effective chaos based algorithm which is specialized for images. A system of two free chaotic functions with high sensitivity to starting states is used to adequately apply confusion and diffusion standards for images with any entropy. One of the functions is utilized for rearranging pixel positions while the other for changing the values of pixels. In the subsequent new pixel association, surrounding pixels with normally close values will go up against significantly different values, making it hard to break the encoded image.

To build resistance of the framework to differential attacks, some logical operations, for example, ex-or and circular rotation are utilized to spread the impact of a slight change in single pixel power of plain picture over numerous pixels in cipher image. The complexity analysis demonstrated that the proposed plan requires less operation than the compared algorithm with respect to key space, security and encryption speed. A variety of analysis and tests, for example, statistical analysis, key-sensitivity and key-space analysis, plain-image sensitivity analysis, and speed test have been completed to show the security and the legitimacy of the proposed calculation. Indeed, even with low entropy images the proposed algorithm has been turned out to be more secure and quicker than the previous algorithm.

\section{Asymmetric Color Image Encryption Plan Utilizing 2D-Discrete Time Map}

AbdurahmanKadir\& Hong Jun Liu (2015) work on image encryption using asymmetric color image using 2D Discrete Time Map is presented. The proposed scheme is a chaos based encryption and has the advantage of distributing the various keys to the various receivers through the mechanism of key changing. The system generates the pseudo irregular arrangements. 
In the encryption plan, firstly make six pseudo-arbitrary clusters to circularly move the red, green and blue fragments by segments and segments independently, and after that diffuse three shading parts by select or operation (XOR). In the unscrambling method, two beginning estimations of Henon guide, the cycle number $m-n+1$, the emphasis times and the control parameters of Henon guide are served as keys. In the decoding strategy, two state variable qualities for the $(n-1)$ cycle, the emphasis number $m-n+1$, and the control parameters $a$ and $\beta$ are served as keys. Generous key space can contradict against savage assault, by evolving one-piece in the plain picture in every encryption can restrict against known-plain content and picked plain content attack, testing comes about exhibit that the arrangement can restrict against commotion attack and trimming attack to a couple degree, so it can be connected in deviated shading image encryption.

\section{An Encryption Technique based on new Mystery Key Algorithm for Color Image}

In the work of Shihua Zhou \&Ziqi Wei (2015) a new mystery (secret) key algorithm is proposed. In order to enhance the security of color image encryption, the mystery key of the encryption the proposed calculation is broke down by various execution analyses. So a new technique for generation of mystery key is presented. The mystery key generation algorithm is given under the operation of DC and AC values in YUV space.

These two qualities are separated from the way toward working DCT of the information after image color space change. Working the new mystery key and the given mystery key together as the introductory estimations of chaotic maps, we can encode the color image in YUV and RGB space through multi-chaotic maps. Here MATLAB is used to simulate the algorithm. They incorporate key security analysis, correlation analysis, the gray histogram analysis, differential attacks, some different attacks, and so on. Keys are generated to generate chaos based iterations and to enhance security. The security analysis illustrates that this proposed algorithm is attainable and viable calculation needs a strong relationship to the actual image, meanwhile, not to uncover its data. It is hard to meet this prerequisite under the given secret key era calculation.

\section{2D Sine Logistic Modulation Map Based Image Encryption}

In the work of Zhongyun Hua \&Yicong Zhou (2014) an image encryption technique using 2D
Sine Logistic Modulation Map (2D-SLMM) is obtained from sine and logistic map is proposed here. On comparing this with current chaotic maps, it has the more extensive disorganized extent, better ergodicity, hyper chaotic property and moderately low usage cost.

To investigate its applications, we propose a chaotic magic transform (CMT) to viably change the picture pixel positions. Joining 2D-SLMM with CMT, we help introduce another picture encryption calculation. A few procedures, including the course, Lyapunov sort and Kolmogorov entropy, have been used to survey the scattered execution of 2D-SLMM. Examination and evaluation comes about have exhibited that 2D-SLMM has the more broad confused achieve, better ergodicity and hyper clamorous property, and that it has favored disorganized execution over existing disordered maps.

To show the execution of 2D-SLMM in security applications, a clamorous enchantment change (CMT) has been displayed. It can quickly rework neighboring pixels inside a image. Using 2D-SLMM and CMT, we have proposed another picture encryption calculation. The exploratory results have shown that the proposed estimation can secure unmistakable sorts of images with a high security level and low time multifaceted nature.

\section{A Quick Image Encryption using 3D Chaotic Cat Maps}

In this paper, GuoshengGu\&Jie Ling (2014) an image encryption procedure using a chaotic 3D cat guide is exhibited in this paper. The plan utilizes mix of change of substitution. The method of the proposed calculation contains the simultaneous operations of pixels' change and pixels' qualities substitution at every iterative stride of the chaotic guide, which making the forward and pivot encryption needs one and just explores of the picture pixels. Moreover, a bother is utilized to take out undesirable constrained accuracy effect of PC in affirmation. Clamorous maps with self-assertive pick of introductory conditions and parameters are utilized to make three discrete tumultuous successions with high affectability by emphases.

Two of the progressions are then used to arrange a two dimensional change by computing new encourages of every pixel of the image and revamp it. By then parts of the third arrangement are truncated and used to frustrate pixel values by consolidated piece elite $\mathrm{OR}$ and cyclic movement operations. To conquer the constrained precision impact, a little aggravation is brought into the 
calculation. The fundamental preferred standpoint of this technique is to give effortlessness and proficiency.

Key space investigation, histogram examination, connection investigation, plain image and keys affectability investigation, data entropy examination and encryption speed investigation are finished to demonstrate the security and the effectiveness of the encryption calculation.

\section{Image Encryption Plan utilizing Chaotic Henon Map}

In this paper Majid Khan \& Tariq Shah (2014) the design of chaos based S-boxes by method for chaotic maps generated more commitment in current ages is proposed here. Here the combination of confusion and diffusion is used. A new technique is proposed for outlining chaotic S-boxes and its application in image encryption. This strategy depends on Henon chaotic map and S8 stage.

The plain text is provided into the blocks and the ciphering is done for the complete block. Two wide ranging thoughts of block ciphers which were proposed by Shannon's are confusion and diffusion. Diffusion is dispersing of impact of plain text bits to cipher text bits with focus to cloud the measurable design of plain text. Confusion is change in which adjustments reliance of data of cipher text on the data of plain text.

In most cipher structures, the confusion and diffusion are achieved by method for round repeat experimental appraisals have been done with complete numerical examination, which uncovers the quality of the anticipated strategy against various sorts of attacks. Furthermore, execution valuation examinations discover that the recommended image encryption calculation is incomprehensibly secured.

The proposed encryption plan is able to do rapid encryption and decryption, which is proper for web encryption and communicate applications.

With the over-abuse of common assets, human being is confronted with progressively climate emergency, for example, energy lack, the a dangerous atmospheric devastation, deforestation, desertification and other ecological issues, so timberland ecological security turns out to be increasingly significant. Environmentalists regularly think the thickness of trees is vital for woodland development, however absence of supporting information inconveniences them. To consider the exact impacts of thickness on estate, scientists need long haul observing on an assortment of biological pointers. Notwithstanding, it is hard to gather naturally and dependably ecological observing information with conventional observing framework.

Web of things gives the specialized establishment to achieving thistask. Web of things is an organization that interfaces anything to the Internet can trade data through Radio Recurrence Identification (RFID), sensor organizations, Global Situating System (GPS) and other data detecting gadgets, as indicated by the concurred conventions, to accomplish insightful recognize, find, track, screen and manage[1][2]. Web of Things has availability for whenever, anyplace, anybody and anything. Along these lines, focusing on the qualities of ranch, we build up an estate observing framework which dependent on Internet.

\section{RESULT}

The results of the review performed are given in the table. The techniques employed in each works, algorithm used, its platform of implementation and the special emphasis given are summarized below. Equally important, parameters of interest in the works and whether encryption key is used are also studied and summarized in Table 1

\section{CONCLUSION}

The security for the computerized images has happened to immense significance as the transmission of advanced items over the open system happens much of the time. To decide the proper encryption plan for particular application frequently includes the thought of specific attributes like encryption speed, memory necessity, security, information quality and extent. In this paper, diverse information encryption procedures that are created as of late, have been considered and investigated to advance further improvement of more encryption techniques to ensure extra security and adaptability.

This is done for uncovering the improvement slant and urging specialists to have a clear prospect of what will be expected sooner rather than later. As an alternative channel to images, video records have numerous components for data covering up such as extensive limit and great intangibility. The test, be that as it may, is to have the capacity to insert into a gathering of images which are exceptionally associated what's more, frequently controlled in a packed structure. 
Table 1.Comparison of Recently Developed Encryption Methods

\begin{tabular}{|c|c|c|c|c|c|c|c|c|}
\hline Reference & Author(s) & $\begin{array}{l}\text { Technique } \\
\text { employed }\end{array}$ & $\begin{array}{l}\text { Algorithm } \\
\text { used }\end{array}$ & $\begin{array}{c}\text { Platform of } \\
\text { implementati } \\
\text { on }\end{array}$ & Emphasis & Use of key & $\begin{array}{l}\text { Parameter } \\
\text { of interest }\end{array}$ & $\begin{array}{c}\text { Year of } \\
\text { publishing/Jour } \\
\text { nal }\end{array}$ \\
\hline 1 & $\begin{array}{l}\text { Manish Kumar \& } \\
\text { Sunil Kumar }\end{array}$ & $\begin{array}{l}\text { Logistic } \\
\text { map \& } \\
\text { cellular } \\
\text { automata }\end{array}$ & $\begin{array}{l}\text { Permutatio } \\
\mathrm{n} \& \\
\text { diffusion }\end{array}$ & Not specified & $\begin{array}{c}\text { To } \\
\text { enhance } \\
\text { security } \\
\& \\
\text { reliabilit } \\
\text { y }\end{array}$ & $\begin{array}{c}\text { To } \\
\text { deduce } \\
\text { chaotic } \\
\text { iterations }\end{array}$ & $\begin{array}{l}\text { Different } \\
\text { security } \\
\text { test }\end{array}$ & 2016 / ieee \\
\hline 2 & $\begin{array}{l}\text { Wenhiro Liu } \\
\& \text { Kehui Sun }\end{array}$ & $\begin{array}{l}\text { Hyper } \\
\text { chaotic } \\
\text { map 2D } \\
\text { SIMM }\end{array}$ & $\begin{array}{l}\text { Chaotic } \\
\text { shift } \\
\text { transform }\end{array}$ & MATLAB & $\begin{array}{c}\text { To } \\
\text { enhance } \\
\text { security }\end{array}$ & $\begin{array}{l}\text { Multiple } \\
\text { keys }\end{array}$ & $\begin{array}{c}\text { Image } \\
\text { pixels } \& \\
\text { fast } \\
\text { encryption }\end{array}$ & 2016 / Elsevier \\
\hline 3 & $\begin{array}{c}\text { Abitha K.A \& } \\
\text { Pradeep K } \\
\text { Bharathan } \\
\end{array}$ & $\begin{array}{c}\text { Chaotic } \\
\text { baker map }\end{array}$ & $\begin{array}{l}\text { Rubik's } \\
\text { cube } \\
\text { algorithm } \\
\end{array}$ & MATLAB & $\begin{array}{c}\text { To } \\
\text { enhance } \\
\text { security } \\
\end{array}$ & $\begin{array}{l}\text { Random } \\
\text { key } \\
\text { selection }\end{array}$ & $\begin{array}{l}\text { NPCR, } \\
\text { correlatio } \\
\mathrm{n}, \mathrm{MSE} \\
\end{array}$ & 2016 / Elsevier \\
\hline 4 & $\begin{array}{c}\text { Dhivya\&Padmapriy } \\
\text { a }\end{array}$ & $\begin{array}{l}\text { Various } \\
\text { mapping } \\
\text { techniques }\end{array}$ & $\begin{array}{l}\text { AES, } \\
\text { 3DES, } \\
\text { IDEA }\end{array}$ & MATLAB & $\begin{array}{c}\text { To } \\
\text { enhance } \\
\text { security }\end{array}$ & $\begin{array}{c}\text { To } \\
\text { confuse } \\
\text { the pixel } \\
\text { pair }\end{array}$ & PSNR & $\begin{array}{l}2016 / \\
\text { Springer }\end{array}$ \\
\hline 5 & SengulDogan & $\begin{array}{l}\text { Various } \\
\text { mapping } \\
\text { techniques, } \\
\text { data hiding }\end{array}$ & $\begin{array}{l}\text { G.A \& } \\
\text { Chaotic } \\
\text { functions }\end{array}$ & MATLAB & $\begin{array}{c}\text { To } \\
\text { enhance } \\
\text { security } \\
\& \\
\text { processi } \\
\text { ng speed }\end{array}$ & $\begin{array}{l}\text { Not } \\
\text { employed }\end{array}$ & PSNR & $\begin{array}{l}2016 / \\
\text { Springer }\end{array}$ \\
\hline 6 & $\begin{array}{l}\text { Zhong Yun Hua, } \\
\text { Yicong Zhou }\end{array}$ & 2D-LASM & $\begin{array}{l}\text { Diffusion \& } \\
\text { confusion }\end{array}$ & MATLAB & $\begin{array}{c}\text { To } \\
\text { enhance } \\
\text { security }\end{array}$ & $\begin{array}{c}\text { To } \\
\text { generate } \\
\text { chaotic } \\
\text { matrix }\end{array}$ & $\begin{array}{c}\text { NPCR, } \\
\text { UACI, } \\
\text { correlatio } \\
\text { n }\end{array}$ & 2016 / Elsevier \\
\hline 7 & $\begin{array}{c}\text { P.Devaraj\&C.Kavit } \\
\text { ha }\end{array}$ & $\begin{array}{l}\text { Modified } \\
\text { std map }\end{array}$ & $\begin{array}{c}\text { Random } \\
\text { diffusion \& } \\
\text { substitutio } \\
\text { n }\end{array}$ & MATLAB & $\begin{array}{c}\text { To } \\
\text { enhance } \\
\text { security } \\
\& \\
\text { complexi } \\
\text { ty }\end{array}$ & $\begin{array}{c}\text { To } \\
\text { generate } \\
\text { S-Box }\end{array}$ & $\begin{array}{c}\text { NPCR, } \\
\text { UACI, } \\
\text { correlatio } \\
\text { n \& } \\
\text { entropy }\end{array}$ & $\begin{array}{c}2016 / \\
\text { Springer } \\
\end{array}$ \\
\hline 8 & $\begin{array}{l}\text { Richardo Francisco } \\
\& \text { Ruben Vazquez }\end{array}$ & $\begin{array}{c}\text { Chaotic } \\
\text { stegnograp } \\
\text { hy }\end{array}$ & $\begin{array}{c}\text { Least } \\
\text { significant } \\
\text { bit }\end{array}$ & Not specified & $\begin{array}{l}\text { To } \\
\text { enhance } \\
\text { security }\end{array}$ & $\begin{array}{c}\text { Not } \\
\text { employed }\end{array}$ & $\begin{array}{c}\text { PSNR, } \\
\text { MSE, } \\
\text { MAXERR, } \\
\text { correlatio } \\
\mathrm{n} \\
\end{array}$ & 2015 / Elsevier \\
\hline 9 & $\begin{array}{l}\text { Kunal Kumar } \\
\text { Kabi\&Arun } \\
\text { Chauhan }\end{array}$ & $\begin{array}{l}\text { Arnold Cat } \\
\text { Map }\end{array}$ & $\begin{array}{l}\text { Chaotic } \\
\text { functions }\end{array}$ & Not specified & $\begin{array}{c}\text { To } \\
\text { enhance } \\
\text { security }\end{array}$ & $\begin{array}{l}\text { Encrypti } \\
\text { on \& } \\
\text { decryptio } \\
\mathrm{n}\end{array}$ & $\begin{array}{c}\text { NPCR, } \\
\text { UACI }\end{array}$ & $\begin{array}{c}2015 / \\
\text { Springer }\end{array}$ \\
\hline 10 & $\begin{array}{l}\text { ErdemYavuz\&Rifat } \\
\text { Yazici }\end{array}$ & $\begin{array}{l}\text { Chaotic \& } \\
\text { logical } \\
\text { functions }\end{array}$ & $\begin{array}{l}\text { Confusion } \\
\& \text { diffusion }\end{array}$ & Not specified & $\begin{array}{c}\text { To } \\
\text { enhance } \\
\text { security }\end{array}$ & $\begin{array}{c}\text { To } \\
\text { increase } \\
\text { complexi } \\
\text { ty }\end{array}$ & $\begin{array}{c}\text { Encryptio } \\
\mathrm{n} \text { speed }\end{array}$ & 2015 / Elsevier \\
\hline 11 & $\begin{array}{l}\text { AbdurahmanKadir } \\
\text { \& Hong Jun Liu }\end{array}$ & $\begin{array}{l}\text { Discrete } \\
\text { time map }\end{array}$ & $\begin{array}{l}\text { Pseudo } \\
\text { random } \\
\text { sequence }\end{array}$ & Not specified & $\begin{array}{c}\text { To } \\
\text { enhance } \\
\text { security }\end{array}$ & $\begin{array}{c}\text { To } \\
\text { generate } \\
\text { iterations }\end{array}$ & $\begin{array}{l}\text { Histogram } \\
\text { \& entropy } \\
\text { analysis } \\
\end{array}$ & 2015 / Elsevier \\
\hline 12 & $\begin{array}{l}\text { Shihua Zhou \&Ziqi } \\
\text { Wei }\end{array}$ & $\begin{array}{c}\text { Multiple } \\
\text { chaotic } \\
\text { map }\end{array}$ & $\begin{array}{c}\text { Chaotic } \\
\text { functions, } \\
\text { DCT } \\
\text { transform }\end{array}$ & MATLAB & $\begin{array}{c}\text { To } \\
\text { enhance } \\
\text { security }\end{array}$ & $\begin{array}{c}\text { To } \\
\text { generate } \\
\text { chaos } \\
\text { based } \\
\text { iterations } \\
\end{array}$ & $\begin{array}{l}\text { Image } \\
\text { pixels }\end{array}$ & $\begin{array}{c}2015 / \\
\text { Springer }\end{array}$ \\
\hline 13 & $\begin{array}{l}\text { Zhongyun Hua } \\
\text { \&Yicong Zhou }\end{array}$ & $\begin{array}{l}\text { Chaotic } \\
\text { magic } \\
\text { transform }\end{array}$ & 2D SLMM & MATLAB & $\begin{array}{c}\text { To } \\
\text { enhance } \\
\text { security, } \\
\text { low time } \\
\text { complexi } \\
\text { ty }\end{array}$ & $\begin{array}{c}\text { To } \\
\text { generate } \\
\text { chaos } \\
\text { based } \\
\text { iterations }\end{array}$ & $\begin{array}{c}\text { NPCR, } \\
\text { UACI, } \\
\text { correlatio } \\
\text { n\& } \\
\text { entropy }\end{array}$ & 2014 / Elsevier \\
\hline 14 & $\begin{array}{l}\text { GuoshengGu\&Jie } \\
\text { Ling }\end{array}$ & $\begin{array}{l}\text { 3D CAT } \\
\text { map }\end{array}$ & $\begin{array}{c}\text { Permutatio } \\
\mathrm{n}, \\
\text { substitutio } \\
\mathrm{n} \& \\
\text { perturbatio } \\
\mathrm{n}\end{array}$ & MATLAB & $\begin{array}{c}\text { To } \\
\text { enhance } \\
\text { security }\end{array}$ & $\begin{array}{c}\text { To } \\
\text { encrypt } \\
\text { image }\end{array}$ & $\begin{array}{l}\text { Image } \\
\text { pixels, } \\
\text { UACI, } \\
\text { NPCR, } \\
\text { entropy }\end{array}$ & 2014 / Elsevier \\
\hline 15 & $\begin{array}{l}\text { Majid Khan \& Tariq } \\
\text { Shah }\end{array}$ & $\begin{array}{l}\text { Henon map } \\
\text { based s } 8 \\
\text { symmetry } \\
\text { group }\end{array}$ & $\begin{array}{l}\text { Confusion } \\
\text { \& diffusion }\end{array}$ & Not specified & $\begin{array}{c}\text { To } \\
\text { enhance } \\
\text { security }\end{array}$ & $\begin{array}{c}\text { To } \\
\text { generate } \\
\text { S-Box }\end{array}$ & Image size & $\begin{array}{l}2014 / \\
\text { Springer }\end{array}$ \\
\hline
\end{tabular}




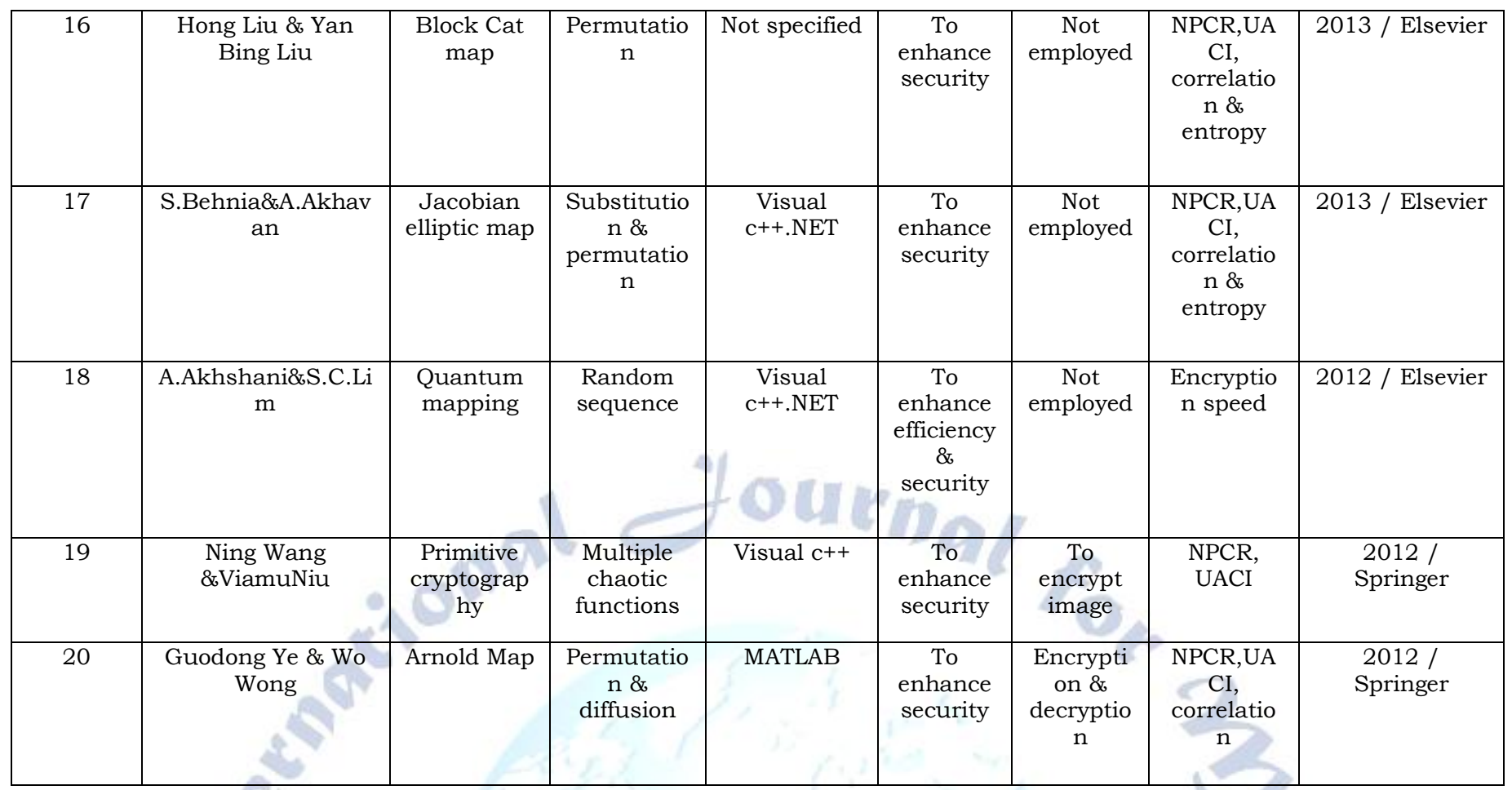

\section{REFERENCES}

[1] Manish Kumar and Sunil Kumar, "Intertwining Logistic Map and Cellular Automata Based Color Image Encryption Model", International Conference on Computational Techniques in Information and Communication Technologies, 978-1-5090-0082-1/16, (2016)

[2] Wenhao Liu and Kehui Sun, "A fast image encryption algorithm based on chaotic map", Optics and Lasers in Engineering(84), p.p 26-36, (2016)

[3] Abitha K.A and Pradeep K Bharathan, "Secure Communication Based On Rubik's Cube Algorithm And Chaotic Baker Map", International Conference on Emerging Trends in Engineering, Science and Technology, p.p 782-789, (2016)

[4] DhivyaRavichandran and PadmapriyaPraveenkumar, "Chaos Based Crossover and Mutation for Securing DICOM Image", Computers in Biology and Medicine, http://dx.doi.org/10.1016/j.compbiomed.2016.03.020, (2016)

[5] SengulDogan, "A new data hiding method based on chaos embedded genetic algorithm for color image", Springer, 10.1007/s10462-016-9459-9, (2016)

[6] Zhongyun Hua and Yicong Zhou, "Image encryption using 2D Logistic-adjusted-Sine map", Information Sciences 00, p.p 1-25, (2016)

[7] P. Devaraj and C. Kavitha, "An image encryption scheme using dynamic S-boxes", Springer Science+Business Media Dordrecht, 10.1007/s11071-016-2934-7, (2016)

[8] Richardo Francisco and Ruben Vazquez, "A steganographic method using Bernoulli's chaotic maps", Computers and Electrical Engineering 000, p.p 1-15, (2015)

[9] Kunal Kumar Kabi and Arun Chauhan, "Implementation of New Framework for Image Encryption Using Arnold 3D Cat Map", Information Systems Design and Intelligent Applications, Advances in Intelligent Systems and Computing 339, p.p 379-384, (2015)

[10] ErdemYavuz and RifatYazici, "A chaos-based image encryption algorithm with simple logical functions", Computers and Electrical Engineering 000, p.p 1-13, (2015)
[11] AbdurahmanKadir and Hong Jun Liu, "Asymmetric color image encryption scheme using 2D discrete-time map", Signal Processing 113, p.p 104-112, (2015)

[12] Shihua Zhou and Ziqi Wei, "An encryption method based on the new secret key algorithm for color image", International Journal of Electronics and Communications, http://dx.doi.org/doi:10.1016/j.aeue.2015.08.010, (2015)

[13] Zhongyun Hua and Yicong Zhou, "2D Sine Logistic modulation map for image encryption", Information Sciences 297, p.p 80-94, (2014)

[14] GuoshengGu and Jie Ling, "A fast image encryption method by using chaotic 3D cat maps", Elsevier-Optik, http://dx.doi.org/10.1016/j.ijleo.2014.05.023, (2014)

[15] Majid Khan and Tariq Shah, "A novel image encryption technique based on Henon chaotic map and S8 symmetric group”, Neural Computing \& Applications, p.p 1717-1722, (2014)

[16] Hong Liu and Yan Bing Liu, "Security assessment on block-Cat-map based permutation applied to image encryption scheme", Optics \& Laser Technology, p.p 313-316, (2013)

[17] S.Behnia and A.Akhavan, "Image encryption based on the Jacobian elliptic maps", The Journal of Systems and Software, p.p 2429-2438, (2013)

[18] A.Akhshani and S.C.Lim, "An image encryption scheme based on quantum logistic map", Communication Nonlinear \& Scientific Numerical Simulation, p.p 4653-4661, (2012)

[19] Ning Wang and ViamuNiu, "Digital Image Encryption Scheme Based on Multiple Chaotic Systems", Springer Science+Business Media LLC, p.p 67-88, (2012)

[20] Guodong Ye and Wo Wong, "An efficient chaotic image encryption algorithm based on a generalized Arnold map", Springer Science+Business Media B.V, p.p 2079-2087, (2012) 